Research paper

\title{
Design of growing points for silver nanoparticles on polypropylene membranes
}

\author{
Ana L. Mendieta-Jiménez a , Pablo Carpio-Martínez a , Fernando Cortés-Guzmán ${ }^{\mathrm{a}, \mathrm{b}}$, \\ Rosa María Gómez-Espinosa ${ }^{\text {a,* }}$ \\ ${ }^{a}$ Centro Conjunto de Investigación en Química Sustentable UAEM-UNAM, Carretera Toluca-Atlacomulco km 14.5 San Cayetano, Piedras Negras, C.P. 50200 Toluca, Estado de \\ México, Mexico \\ b Instituto de Química, Universidad Nacional Autónoma de México, Universidad 300, Ciudad Universitaria, Ciudad de México 04510, Mexico
}

\section{A R T I C L E I N F O}

Article history:

Received 30 October 2017

In final form 7 January 2018

Available online 8 January 2018

\section{Keywords:}

Silver nanoparticles

Nucleation point

Polypropylene membrane

Quantum chemical topology

\begin{abstract}
A B S T R A C T
The nucleation process of a nanoparticle requires an environment that stabilizes the initial seed and favors the growth action. In this paper, we present a specific design of growing points for silver nanoparticles based on the well-known affinity of the silver to the chlorine atoms and to aromatic groups by cation- $\pi$ interactions. [2-(vinylphenyl)ethyl]chloromethylphenylsilane was proposed as growing point of nanoparticles, which has been synthetized and grafted on a polypropylene membrane. Nanoparticles were synthesized by chemically reducing an $\mathrm{AgNO}_{3}$ solution with $\mathrm{NaBH}_{4}$ and the so synthesized nanoparticles were also fully characterized. Using DFT-QTAIM calculations a model of the initial seed and a growth mechanism were proposed.
\end{abstract}

(c) 2018 Elsevier B.V. All rights reserved.

\section{Introduction}

In recent years, the study and preparation of inorganic crystalline particles in the nanometric scale has attracted considerable attention from both fundamental and applied research [1]. Metal nanoparticles of silver, gold and copper have been the focus of great interest because of their unique optical properties determined by the collective oscillations of electron density, termed plasmons [2,3]. Several methods to obtain nanoparticles have been recently reported, using several templates and experimental conditions [4]. One of them is the impregnation of the metal ion, which consists in the reduction of any metal ion to metal zero valence at room temperature, atmospheric pressure and using water as solvent [5]. Also, the use of a polymer material as template to grow nanomaterials has become popular due to the versatility of polymeric matrixes [6]. It is possible to modify the activity of polymers by electroless plating in fabrication of advanced nanomaterials [7]. Polymeric membranes can be also used as support of metal particles due to their porous structure, produces a good dispersion of the particles over the membrane surface and allows the reactants to flow through it. Membranes can be modified by grafting reaction with several molecules to modulate the physical and chemical

\footnotetext{
* Corresponding author.

E-mail address: rmgomeze@uaemex.mx (R.M. Gómez-Espinosa).
}

properties [8]. In this work, we modified a polypropylene membrane to be used as template for the nanoparticle growing.

The nucleation process of a nanoparticle requires a suitable environment to stabilize the initial seed and to favor the growth action. The metal nucleation in the impregnation method is dominated by weak or non-covalent interactions between metal ions and the solvent, solution or Supporting material [9]. Usually soft electron donors such as amine, pyridine, pyrazole or thiol functional group are used to create a stabilizing growing environment [10]. In this work, we explore an alternative approach to stabilize nanoparticles in non-polar environment, creating specific growing points (GP) for silver nanoparticles based on the affinity between the silver cations and the aromatic rings, and on the ion-dipole interaction with the $\mathrm{Si}-\mathrm{Cl}$ bonds. $\mathrm{The}^{+}-\pi$ interactions has been widely studied, both experimentally [11] and theoretically [12]. The $\mathrm{Ag}^{+}$-benzene interaction presents a binding energy around 1.34 and $2.63 \mathrm{kcal} / \mathrm{mol}$, [13] and shows a cooperative effect in the presence of several aromatic ring as observed in the argentivorous molecules, which have aromatic side-arms as 'petals that caught the $\mathrm{Ag}^{+}$ions in the way insectivorous plants catch insects' [14]. In this way, the GP proposed in this work acts as silver cations trap site, with the advantage of the large flexibility that a silicon atom can provide as pivot point. Then, after a silver cation has been captured within a GP, it is possible that other silver atoms congregate around it, by argentophilic interactions, [15] after chemical reduction to produce clusters or nanoparticles. 
In this work, the GP was obtained by a modification of polypropylene membrane with [2-(vinylphenyl)ethyl]chlorome thylphenylsilane (ECMPS), which was synthesized by the first time. The nanoparticles were grown, in the modified membrane, by chemical reduction of a solution of $\mathrm{AgNO}_{3}$ by $\mathrm{NaBH}_{4}$. ECMPS exhibits three possible sites of interaction with $\mathrm{Ag}^{+}$ions, a $\mathrm{Si}-\mathrm{Cl}$ bond and two phenyl rings, which behave as trap of silver cations and growing point for nanoparticles.

\section{Experimental Methods}

\subsection{Synthesis of methylphenylsilane (MPS)}

Methylphenylsilane was synthesized by a reported procedure, [16] by the reaction between dichloromethylphenylsilane and lithium aluminum hydride in the presence of anhydrous ether. Into a three-necked flask with constant stirring, a solution of dichloromethylphenylsilane $(0.0372 \mathrm{~mol}$ of $12 \mathrm{ml}$ of anhydrous ether) was added to $\mathrm{LiAlH}_{4}(0.0372 \mathrm{~mol})$ and refluxed for $4 \mathrm{~h}$. Then, a solution of hydroquinone $\left(9.08 \times 10^{-4} \mathrm{~mol}\right.$ in $8 \mathrm{ml}$ of distilled water) was added to remove unreacted $\mathrm{LiAlH}_{4}$. Finally, methylphenylsilane was extracted with ether from the reaction solution.

\subsection{Synthesis of monomer of [2-(vinylphenyl)ethyl] chloromethylphenylsilane (ECMPS)}

In a round flask, equipped with a stirrer and under $\mathrm{N}_{2}$ atmosphere, divinylbenzene (DVB, $8.42 \times 10^{-3} \mathrm{~mol}$ ), dichloromethylphenylsilane (DCMPS, $4.27 \times 10^{-3} \mathrm{~mol}$ ) and 2,2azobisisobutyronitrile (AIBN, $1.58 \times 10^{-4} \mathrm{~mol}$ ) were mixed, then MPS $\left(2.67 \times 10^{-3} \mathrm{~mol}\right)$ was added. The mixture was then left under constant stirring for $12 \mathrm{~h}$.
2.3. Polymerization of ECMPS onto the polypropylene membrane to obtain modified membrane PP-ECMPS

A solution prepared with $5 \mathrm{~mol}$ of ECMPVS, $1.1 \mathrm{~mol}$ of DVB (as crosslinker), $0.093 \mathrm{~mol}$ of 2,2-dimethoxy-2-phenylacetophenone (DMPA) and $1 \mathrm{ml}$ of dimethylformamide (DMF), was impregnated onto the surface of the polypropylene membrane (from $3 \mathrm{M}$ Company with porosity of $84.6 \%$, pore diameter of $0.45 \mu \mathrm{m}$ and thickness of $114 \mu \mathrm{m})$, which was placed between two films and subjected to $300 \mathrm{~nm}$ UV-vis radiation for $13 \mathrm{~h}$. Then the membrane was washed with THF and rinsed with methanol. Finally, the material was placed under high vacuum for $60 \mathrm{~min}$.

\subsection{Synthesis of silver particles onto PP-ECMPS}

The silver metal particles were synthesized by the impregnation-reduction method, using $\mathrm{AgNO}_{3}$ as precursor and $\mathrm{NaBH}_{4}$ as the reducing agent. PP-ECMFVS was submerged into a $5 \mathrm{mM} \mathrm{AgNO}_{3}$ solution, varying the immersion time (from 10 to $30 \mathrm{~min}$ ). Then, the membrane was rinsed with ethanol to remove not retained $\mathrm{Ag}^{+}$ions. Subsequently, the membrane was placed into a $\mathrm{NaBH}_{4}$ solution ( $0.1 \%$ by weight) for $20 \mathrm{~min}$, then it was washed with deionized water and dried under high vacuum for $2 \mathrm{~h}$.

\subsection{Computational methods}

The computational study was performed at M05-2X/LANL2DZ [17] theoretical level as implemented in Gaussian 09 program [18]. Full optimization of every structure was performed and the stable stationary point was confirmed by a frequency calculation. For each structure, a wave function was obtained to calculate local and integrated properties of electron density with AIMAll [19].

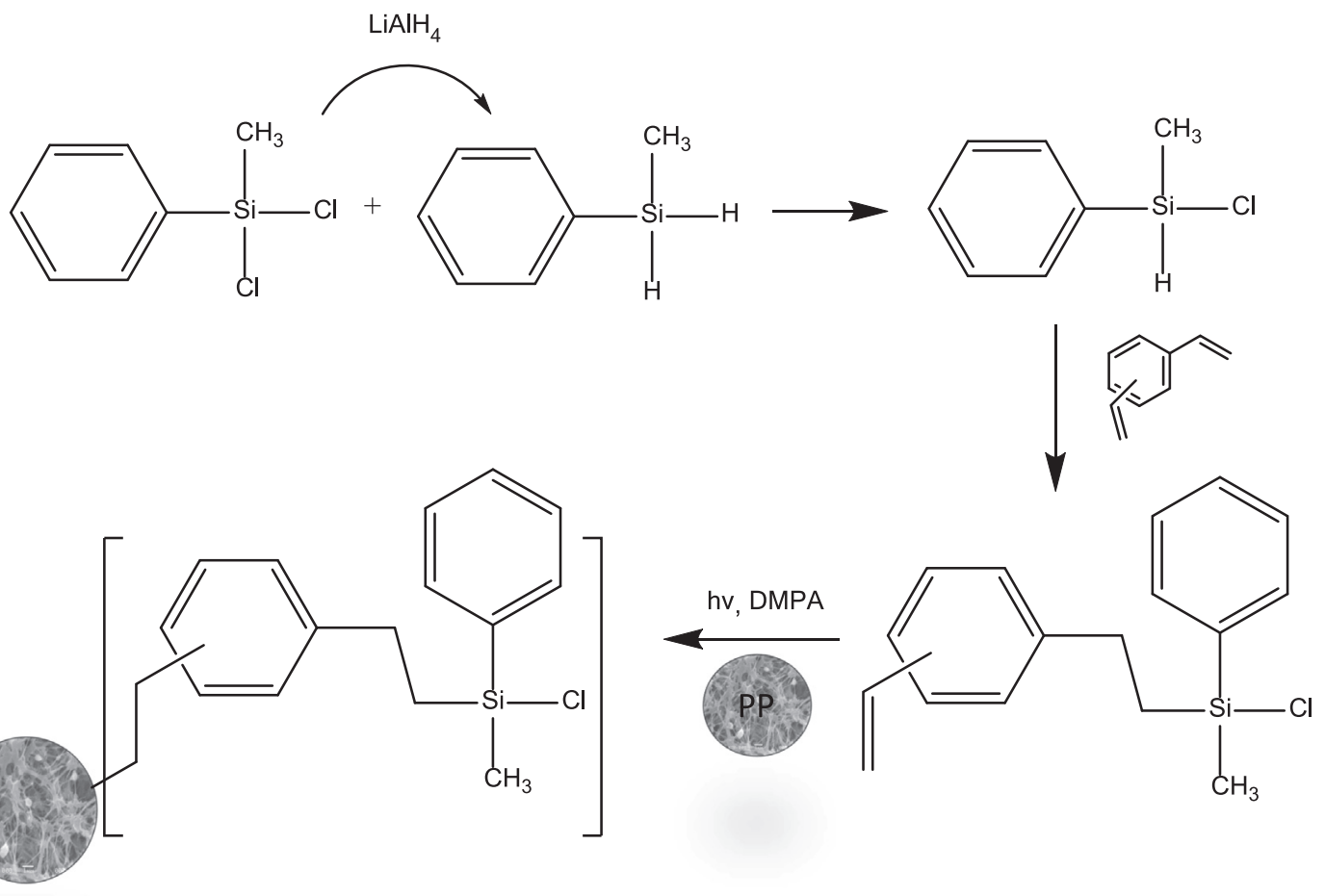

Fig. 1. Synthetic route to obtain ECMPS grafted onto the polypropylene membrane. 


\section{Results}

Fig. 1 presents the synthetic route to obtain ECMPS and grafting it into the polypropylene membrane (PP). The reduction of commercial dichloromethylphenylsilane by lithium aluminium hydride gave methylphenylsilane. Redistribution product between dichloromethylphenylsilane and methylphenylsilane, followed by a radical reaction with divinylbenzene produces ECMPS, using AIBN as catalyst [20]. As far as we know there are not previous reports of the synthesis of ECMPS.

The ECMPS monomer was grafted onto PP by photopolymerization catalyzed by 2,2-Dimethoxy-2-phenylacetophenone (DMPA) and UV light (300 nm), using DMF as solvent. Synthesis of silver particles was performed by impregnation of $\mathrm{PP}$ with a $\mathrm{AgNO}_{3}$ solution, followed by a reduction using $\mathrm{NaBH}_{4}$ as reducing agent.

Here, we briefly describe the characterization of the membrane after each step of the synthesis and the grafting reaction. The IR spectrum of methylphenylchlorosilane shows a $\mathrm{Si}-\mathrm{H}$ band in $2137 \mathrm{~cm}^{-1}$. In addition, other signals are also observed at 3009 $\mathrm{cm}^{-1}((\mathrm{Ph})-\mathrm{H}), 2968 \mathrm{~cm}^{-1}\left(\mathrm{CH}_{3}\right), 1632-1594 \mathrm{~cm}^{-1}$ (Ph-Si) and $1263 \mathrm{~cm}^{-1}\left(\mathrm{Si}-\mathrm{CH}_{3}\right)$. The RMN ${ }^{1} \mathrm{H}$ spectrum presents the signals of expected groups: $0.4 \mathrm{ppm}\left(\mathrm{Si}-\mathrm{CH}_{3}\right), 4.35 \mathrm{ppm}(\mathrm{Si}-\mathrm{H})$ and $7.3-$ $7.6 \mathrm{ppm}((\mathrm{Ph})-\mathrm{H})$. ECMPS has IR signals in $1629 \mathrm{~cm}^{-1}$ (Ph-Si), $1260 \mathrm{~cm}^{-1}\left(\mathrm{Si}-\mathrm{CH}_{3}\right), 544,479$ and $432 \mathrm{~cm}^{-1}(\mathrm{Si}-\mathrm{Cl})$. The RMN ${ }^{1} \mathrm{H}$ presents six characteristic signal: $0.45 \mathrm{ppm}\left(\mathrm{Si}-\mathrm{CH}_{3}\right), 2.6 \mathrm{ppm}(\mathrm{dt}$, $\mathrm{Si}-\mathrm{CH}_{2}$ ), $4.35 \mathrm{ppm}$ (dt, $\mathrm{CH}_{2}-\mathrm{Ph}$ ), 5.25 and $5.75 \mathrm{ppm}$ (d, vinyl protons), 6.8 and $7.3 \mathrm{ppm}$ ( $\mathrm{m}$, aromatic protons). The evidence of ECMPS being grafted onto the PPM was the weight increase and the FT-IR-ATR bands of the modified membrane at: 3020 (Ph-C$\mathrm{Si}), 2953-2840\left(\mathrm{CH}_{3}-\mathrm{CH}_{2}-\right), 1685-1602 \mathrm{~cm}^{-1}(\mathrm{Ph}-\mathrm{Si}), 1263 \mathrm{~cm}^{-1}$ $\left(\mathrm{Si}-\mathrm{CH}_{3}\right), 580,480$ and $438 \mathrm{~cm}^{-1}(\mathrm{Si}-\mathrm{Cl})$. Also in the scanning electronic microscopy (SEM) images, it is possible to observe a porous reduction by thickening of the fibers. BET multipoint analysis indicates that the unmodified membrane has $11.97 \mathrm{~m}^{2} / \mathrm{g}$ of surface
(A)

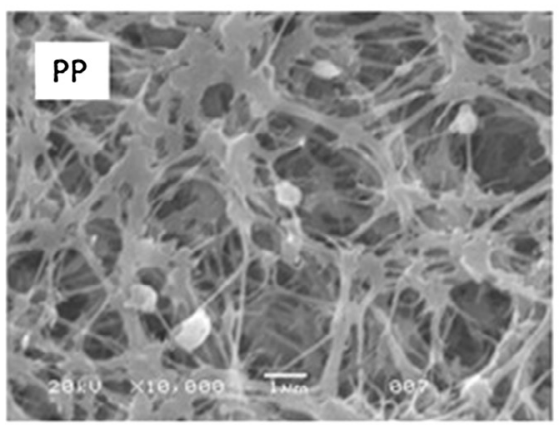

(B)

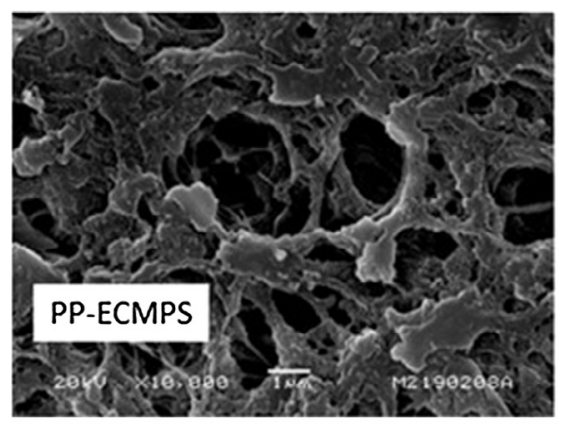

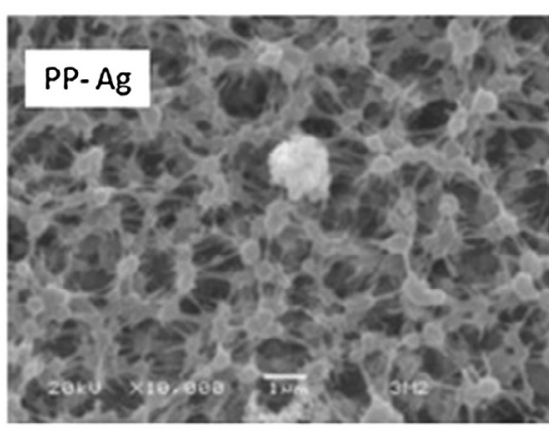

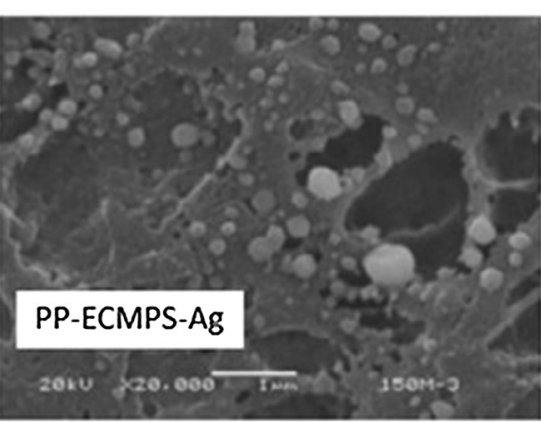

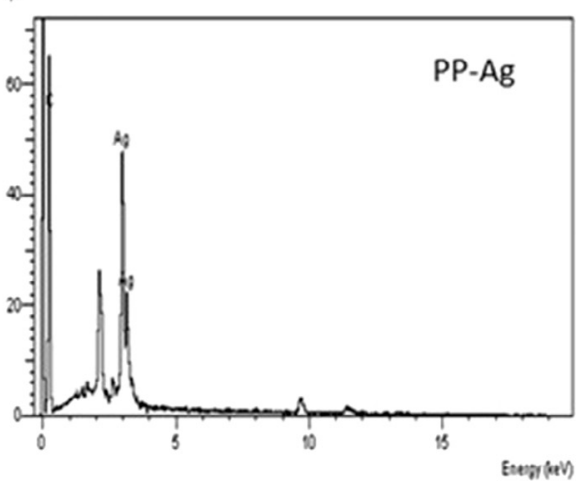

$\omega$

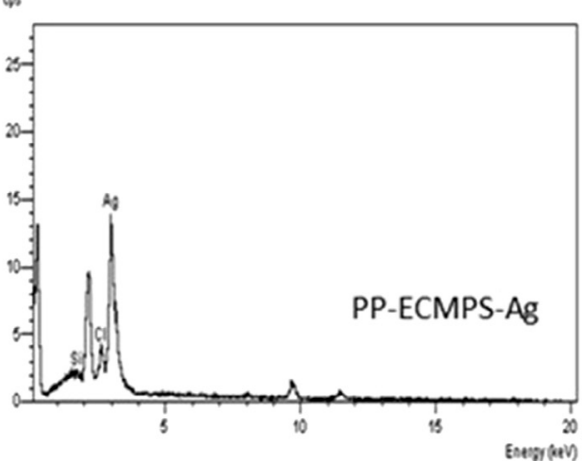

Fig. 2. SEM images and EDS analysis of (A) unmodified membrane supporting agglomerates of silver clusters, (B) modified membrane supporting silver nanoparticles.
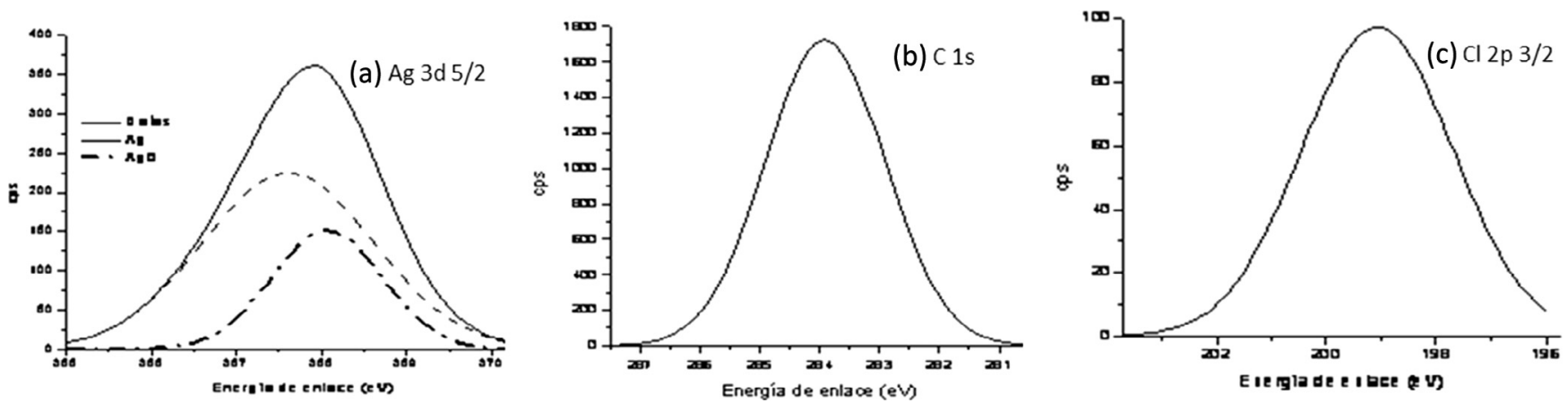

Fig. 3. XPS analysis of modified membrane supporting silver nanoparticles. 
area whereas modified membrane has $52.66 \mathrm{~m}^{2} / \mathrm{g}$. Although it is well known that $\mathrm{Si}-\mathrm{Cl}$ bond undergoes hydrolysis, [21] our results shows ECMPS remains unchanged after the impregnation and reduction processes with water as solvent. To hydrolyze the $\mathrm{Si}-\mathrm{Cl}$ bond on the modified membrane it is necessary to raise the temperature to boiling point of water as shown in IR spectra in Supporting information, where it is possible to observe the $\mathrm{Si}-\mathrm{OH}$ signal at $1016 \mathrm{~cm}^{-1}$. It seems that the $\mathrm{Si}-\mathrm{Cl}$ bond is stabilized within the membrane.

The best conditions for the synthesis of nanoparticles include the immersion of the membranes in a solution of $\mathrm{AgNO}_{3}(5 \mathrm{mM})$

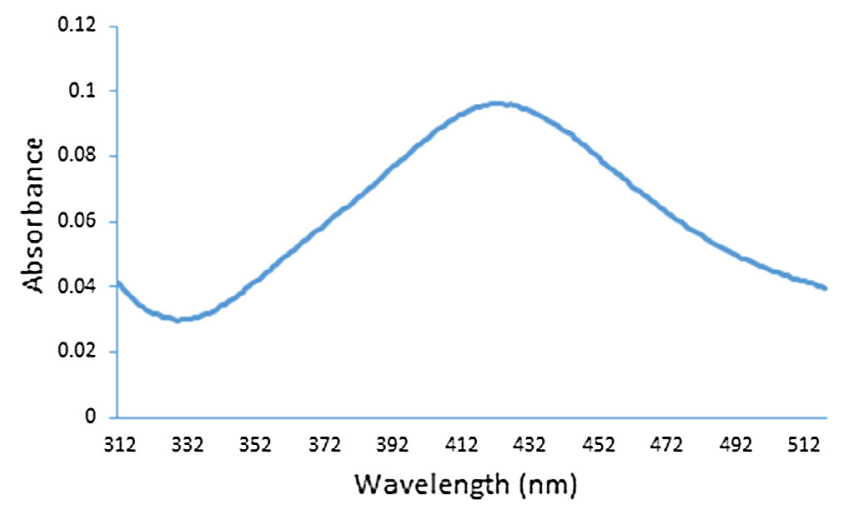

Fig. 4. Surface plasmon resonance of silver nanoparticles.
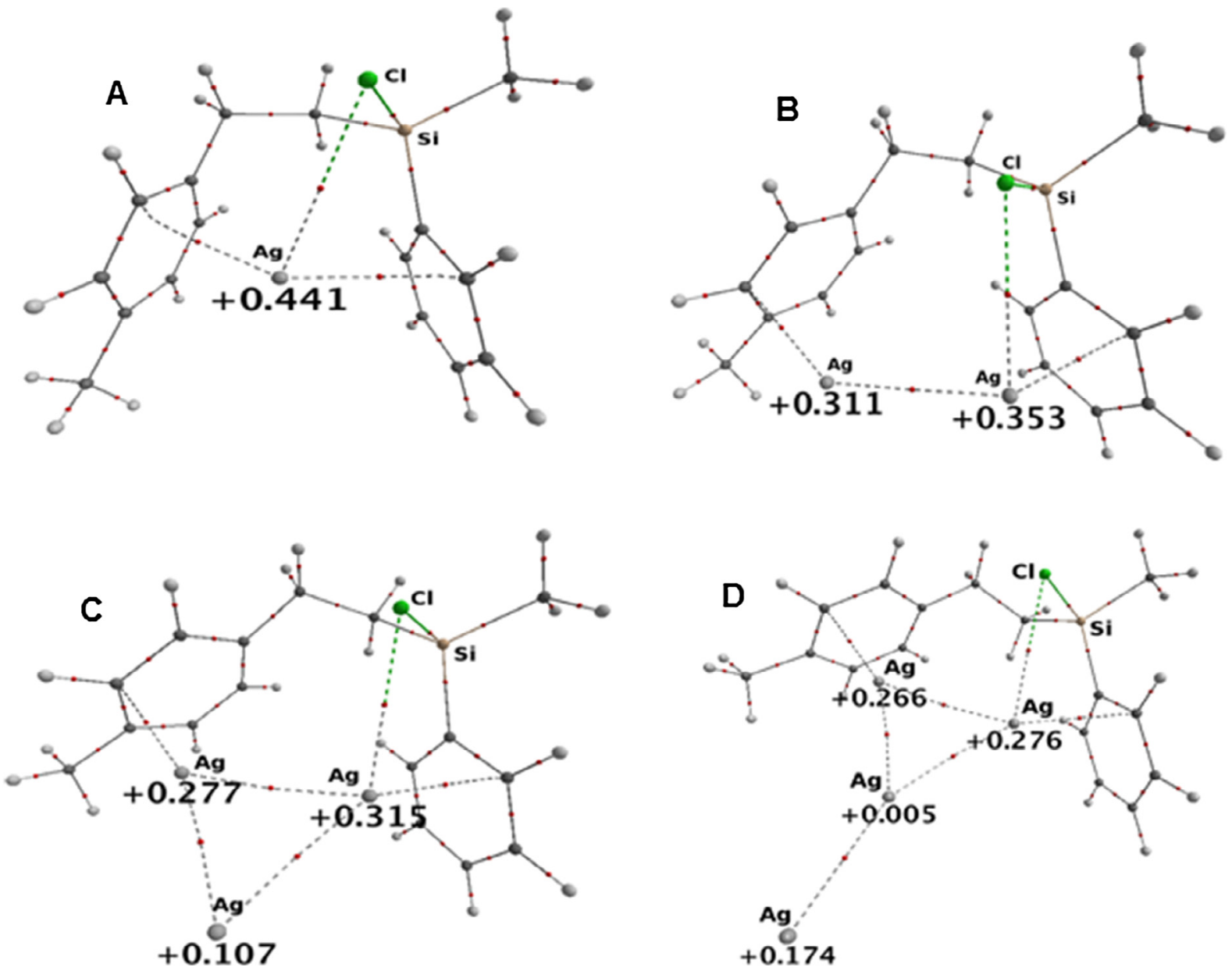

for $30 \mathrm{~min}$, then the impregnated membranes were introduced into an aqueous solution of $\mathrm{NaBH}_{4}(0.1 \mathrm{M})$ for $20 \mathrm{~min}$. Finally, the samples were rinsed with methanol and dried at high vacuum for $2 \mathrm{~h}$. The characterization of nanoparticles was performed by microscopy, X-ray photoelectronic spectroscopy (XPS) and UVvis spectroscopy. SEM images of unmodified PP membrane show just few agglomerates of silver particles, indicating that it is important to functionalize the membrane (Fig. 2A), while modified membrane (PP-ECMPS) presents silver particles with defined shape of nanometric size (Fig. 2B). In both cases, energy dispersion analysis (EDS), which provides information of elemental composition, displays signals for silver, chlorine and silicon.

The modified membrane was analyzed by UV diffuse reflection and showing an absorption band at $432 \mathrm{~nm}$, which corresponds to silver particles smaller than $100 \mathrm{~nm}$ of size (Fig. 3). Silver particles were extracted by sonication during $6 \mathrm{~h}$ and UV-visible absorption spectra were obtained, which shows a peak at $418 \mathrm{~nm}$, which is characteristic of the surface plasmon resonance of absorption of Ag nanoparticles [22].

The XPS analysis indicates that the silver is supported on the modified membrane, and shows a peak at $368.08 \mathrm{eV}$ corresponding to $\mathrm{Ag} 3 \mathrm{~d}$ silver $5 / 2$, a second peak at $283.91 \mathrm{eV}$ assigned to carbon $\mathrm{C}$ $1 \mathrm{~s}$, and a last peak in $199.07 \mathrm{eV}$ attributed to chlorine $\mathrm{Cl} 2 \mathrm{p} \mathrm{3/2}$, (Fig. 4).

To understand the growing process of nanoparticles on grafted PP-ECMPS, we suggest a mechanism below described. When the modified membrane is within the solution of $\mathrm{AgNO}_{3}$, some $\mathrm{Ag}^{+}$ions are trapped by functional groups of ECMPS, which donate electron

Fig. 5. Molecular graph and atomic charges of silver atoms of $\left.(A) G P-A g^{+},(B) G P-A g^{+}-A g^{0}, C\right) G P-A g^{+}-\left(A g^{0}\right)_{2}$ and $\left.D\right) A g^{+}-\left(A g^{0}\right)_{3}$. 
density to the cations thus changing their redox potential and forming the GP. Once the reducing agent is added to the impregnated membrane, free $\mathrm{Ag}^{+}$ions in solution are reduced and linked around not reduced $\mathrm{Ag}^{+}$ions at the GP, assembling a silver cluster. It is possible that several clusters, linked to ECMPS, merge until a nanoparticle is formed.

To give theoretical support to the proposed mechanism, we carried out a computational study at M05-2X/LANL2DZ [17] theoretical level with Gaussian 09 program, [23] using [2-(4methylphenyl)ethyl]chloromethylphenylsilane as a model of GP. The first step of the mechanism is the impregnation of $\mathrm{Ag}^{+}$into the grafted ECMPS, therefore we studied the interaction between the cation and GP model, which presents an interaction energy of $63.54 \mathrm{kcal} / \mathrm{mol}$, which is $61.71 \mathrm{kcal} / \mathrm{mol}$ more stable than $\mathrm{Ag}^{0}$ ECMPS interaction and $26.26 \mathrm{kcal} / \mathrm{mol}$ more stable than that experimentally observed for $\mathrm{Ag}^{+}$-benzene, due to the cooperative effect of the interactions with the two aromatic rings and the chlorine atom [24]. The presence of interactions was determined by the topology of the electron density, [25] which was calculated with AIMAll program [26]. From the molecular graph [27] of $\mathrm{Ag}^{+}-$ model complex (Fig. 5A), it is possible to observe that the silver cation binds to the chlorine atom and to both phenyl rings by a $\pi$-cation- $\pi$ interaction. The $\mathrm{Ag}-\mathrm{Cl}$ distance is $3.098 \AA$ whereas the distance between the cation and the phenyl rings are $2.480 \AA$ and $2.475 \AA$, respectively. Once an $\mathrm{Ag}^{+}$is linked to ECMPS, the growing of a nanoparticle starts with an addition of $\mathrm{Ag}^{0}$ atoms to form an $\mathrm{Ag}^{+}-\left(\mathrm{Ag}^{0}\right)_{\mathrm{n}}$ clusters during the reduction process. We calculated the redox potential [28] of silver cation coordinated to ECMPS, which is $-2.51 \mathrm{~V}$ whereas the potential for $\mathrm{Ag}^{+}$in solution is $-1.9 \mathrm{~V},[29]$ supporting the growing model. Fig. $5 \mathrm{~B}, \mathrm{C}$ and $\mathrm{D}$ shows $\mathrm{Ag}^{+}-\mathrm{Ag}^{0}, \mathrm{Ag}^{+}-\left(\mathrm{Ag}^{0}\right)_{2}$ and $\mathrm{Ag}^{+}-\left(\mathrm{Ag}^{0}\right)_{3}$ systems respectively. The first complex shows a $\pi-\mathrm{Ag}-\mathrm{Ag}-\pi$ interaction with an $\mathrm{Ag}-\mathrm{Ag}$ distance of $2.7546 \AA$, whereas the second one presents an $\mathrm{Ag}_{3}$ three-member ring, where the $\mathrm{Ag}$ - $\mathrm{Ag}$ distances are $2.786 \AA$ and $2.720 \AA$. These distances fully agree with those found for argentophilic bonding. ${ }^{15}$ The positive charge of the cation is delocalized to the organic structure and the silver atoms as shown in Fig. 5. Once the $\mathrm{Ag}^{+}-\left(\mathrm{Ag}^{0}\right)_{2}$ is formed, the rest of the growing occurs outside the GP as shown in Fig. 5D. The $\mathrm{Ag}^{+}-\left(\mathrm{Ag}^{0}\right)_{\mathrm{n}}$ clusters were grown until $n=10$, finding several configurations for each $n$ and several growing paths, which are presented in Supporting information. We are currently conducting more experiments to support this mechanism.

\section{Conclusions}

In this paper, we report the design and development of an environment suitable to stabilize the initial seed thus favoring the growth action based on well-known affinity of the silver to the chlorine atoms and to aromatic groups by cation- $\pi$ interactions. [2-(vinylphenyl)ethyl]chloromethylphenylsilane was synthesized (for the first time) and grafted onto a polypropylene membrane with a photochemical reaction. In this material the nanoparticles were synthesized by chemical reduction of an $\mathrm{AgNO}_{3}$ solution by $\mathrm{NaBH}_{4}$. The nanoparticles were fully characterized by several techniques. The growing difference between the unmodified and modified membranes confirm that the grafted monomer provided an adequate environment to obtain nanoparticles. A growing mechanism was proposed by computational methods. The initial step in such mechanism involves the formation of a Growing-Point- $\mathrm{Ag}^{+}$ complex, followed by the aggregation of silver to produce $\mathrm{Ag}^{+}$$\left(\mathrm{Ag}^{0}\right)_{n}$ clusters. The formation of the nanoparticles is directed by the change of the redox potential modulated by the functional groups of the grafted monomer.

\section{Acknowledgments}

Authors would like to thank the 3M Company for providing the propylene membrane, Dr. Uvaldo Hernández Balderas, María Citlalit Martínez Soto for technical assistance, A.R. Vilchis Nestor for SEM microscopy. Finally, the financial support of SIyEA-UAEMex project 4311, PAPIIT-UNAM project IN208113 and CONACYT project 220392 is also acknowledged.

\section{Appendix A. Supplementary material}

Supplementary data associated with this article can be found, in the online version, at https://doi.org/10.1016/j.cplett.2018.01.013.

\section{References}

[1] S.H.S. Nalwa, Nanoestructured Materials and Nanotechnology, Concise ed., Academic Press, 2002.

[2] V.K. Sharma, R.A. Yngard, Y. Lin, Adv. Colloid Interf. Sci. 145 (2009) 83-96.

[3] H. Choi, S.-J. Ko, Y. Choi, P. Joo, T. Kim, B.R. Lee, J.-W. Jung, H.J. Choi, M. Cha, J.-R. Jeong, et al., Nat. Photonics 7 (2013) 732-738.

[4] H. Won, H. Nersisyan, C.W. Won, J.-M. Lee, J.-S. Hwang, Chem. Eng. J. 156 (2010) 459;

W. Yan, R. Wang, Z. Xu, J. Xu, L. Lin, Z. Shen, Y. Zhou, J. Mol. Catal. A: Chem. 255 (2006) 81 ;

I. Capek, Adv. Colloid Interf. Sci. 110 (2004) 49-74.

F. Bonet, S. Grugeon, R. Herrera-Urbina, K. Tekeia-Elhsissen, J.M. Tarascon, Solid State Sci. 4 (2002) 665;

J. Sun, Y. Jing, Y. Jia, M.T.C. Belin, Mat. Lett. 59 (2005) 3933;

L. Jiang, A. Wang, Y. Zhao, J. Zhang, J. Zhu, J. Inorg. Chem. Commun. 7 (2004) 506 ;

H. Lu, X.L. Liu, X.F. Wang, X.F. Qian, J. Yin, Z.K. Zhu, Mat. Lett. 81 (2003) 104; S. Sarkar, E. Guibal, F. Quignard, A.K. SenGupta, J. Nanopart. Res. 14 (2) (2012) 715 :

S. Bala, R. Mondal, ChemistrySelect 2 (1) (2017) 389-398.

[5] I. Pastoriza-Santos, L.M. Liz-Marzan, Pure Appl. Chem. 72 (2000) 83; R. Patakfalvi, Z. Viranyi, I. Dekany, Colloid Polym. Sci. 283 (2004) 299; M. Kim, J.-W. Byun, D.-S. Shin, Y.-S. Lee, Mater. Res. Bull. 44 (2009) 334.

[6] J. Zhang, S. Xu, E. Kumacheva, J. Am. Chem. Soc. 126 (2004) 7908-7914.

[7] F. Muench, A. Eils, M.E. Toimil-Molares, Surf. Coat. Technol. 242 (2014) 100108.

[8] M. Zhang, M. Drechsler, A.H.E. Muller, Chem. Mater. 16 (2004) 537-543.

[9] R. Patakfalvi, S. Papp, I.J. Dekany, Nanoparticles Res. 9 (2007) 353-364; C. Luo, Y. Zhang, X. Zeng, Y. Zeng, Y.J. Wang, Colloid Interf. Sci. 288 (2005) 444448;

M.M. Oliveira, D. Ugarte, D. Zanchet, A.J. Zarbin, Colloid Interf. Sci. 292 (2005) 429-435;

W. Zhang, X. Qiao, J. Chen, Chem. Phys. 330 (2006) 495-500;

W. Zhang, X. Qiao, J. Chen, Colloids Surf. A: Physicochem. Eng. Asp. 299 (2007) 22-28;

Y. Xiong, A.R. Siekkinen, J. Wang, Y. Yin, M.J. Kim, Y. Xia, J. Mater. Chem. 17 (2007) 2600-2602.

[10] S. Bala, R. Mondal, ChemistrySelect 2 (1) (2017) 389-398.

[11] P. Pyykkö, Chem. Rev. 97 (3) (1997) 597-636.

[12] D. Kim, S. Hu, P. Tarakeshwar, K.S. Kim, J.M. Lisy, J. Phys. Chem. A 107 (8) (2003) 1228-1238.

[13] J.M. Maier, P. Li, J. Hwang, M.D. Smith, K.D. Shimizu, J. Am. Chem. Soc. 137 (25) (2015) 8014-8017.

[14] Y. Habata, M. Ikeda, S. Yamada, H. Takahashi, S. Ueno, T. Suzuki, S. Kuwahara, Org. Lett. 14 (17) (2012) 4576-4579.

[15] H. Schmidbaur, A. Schier, Angew. Chem. Int. Ed. 54 (3) (2015) 746-784.

[16] A.B. Chopa, J.C. Podesta, Anal. Asoc. Argenton 65 (1977) 181.

[17] M. Harb, F. Rabilloud, D. Simon, A. Rydlo, S. Lecoultre, F. Conus, V. Rodrigues, C. Félix, J. Chem. Phys. 129 (2008) 194108; P.J. Hay, R. Wadt Willar, J. Chem. Phys. 82 (1985) 299; D. Silverstein, L. Jenssen, J. Chem. Phys. 132 (2010) (194302-1).

[18] M.J. Frisch, G.W. Trucks, H.B. Schlegel, G.E. Scuseria, M.A. Robb, J.R. Cheeseman, G. Scalmani, V. Barone, G.A. Petersson, H. Nakatsuji, X. Li, M. Caricato, A. Marenich, J. Bloino, B.G. Janesko, R. Gomperts, B. Mennucci, H.P. Hratchian, J.V. Ortiz, A.F. Izmaylov, J.L. Sonnenberg, D. Williams-Young, F. Ding, F. Lipparini, F. Egidi, J. Goings, B. Peng, A. Petrone, T. Henderson, D. Ranasinghe, V.G. Zakrzewski, J.Gao, N. Rega, G. Zheng, W. Liang, M. Hada, M. Ehara, K. Toyota, R. Fukuda, J. Hasegawa, M. Ishida, T. Nakajima, Y. Honda, O. Kitao, H. Nakai, T. Vreven, K. Throssell, J.A. Montgomery, Jr., J.E. Peralta, F. Ogliaro, M. Bearpark, J. J. Heyd, E. Brothers, K.N. Kudin, V.N. Staroverov, T. Keith, R. Kobayashi, J. Normand, K. Raghavachari, A. Rendell, J.C. Burant, S.S. Iyengar, J. Tomasi, M. Cossi, J.M. Millam, M. Klene, C. Adamo, R. Cammi, J.W. Ochterski, R.L. Martin, K. Morokuma, O. Farkas, J.B. Foresman, D.J. Fox, Gaussian 09, Revision A.02, Gaussian, Inc., Wallingford CT, 2016.

[19] AIMAll (Version 17.01.25), Todd A. Keith, TK Gristmill Software, Overland Park KS, USA, 2017 (aim.tkgristmill.com). 
[20] U. Gerigk, M. Gerlach, W.P. Neumann, R. Vieler, V. Weintritt, Synthesis (1990) 448.

[21] Y. Fujimoto, M. Heishi, A. Shimojima, K. Kuroda, J. Mater. Chem. 15 (2005) 5151-5157.

[22] K.L. Kelly, E. Coronado, L.L. Zhao, G.C. Schatz, J. Phys. Chem. B 107 (2003) 668; I.O. Sosa, C. Noguez, R.G. Barrera, J. Phys. Chem. B 107 (2003) 6269;

Y. Mizukoshi, T. Fujimoto, Y. Nagata, R. Oshima, Y. Maeda, J. Phys. Chem. B 104 (2000) 6028

J.J. Mock, M. Barbic, D.R. Smith, D.A. Schultz, S. Schultz, J. Chem. Phys. 116 (2002) 6755;

J. Cheng, J. Wang, X. Zhang, Y. Jin, Mater. Chem. Phys. 108 (2008) 421;

X. Tian, W. Wang, G. Cao, Mat. Lett. 61 (2007) 130.

[23] M.J. Frisch, G.W. Trucks, H.B. Schlegel, G.E. Scuseria, M.A. Robb, J.R. Cheeseman, G. Scalmani, V. Barone, B. Mennucci, G.A. Petersson, H. Nakatsuji, M. Caricato, X. Li, H.P. Hratchian, A.F. Izmaylov, J. Bloino, G. Zheng, J.L. Sonnenberg, M. Hada, M. Ehara, K. Toyota, R. Fukuda, J. Hasegawa, M. Ishida, T. Nakajima, Y. Honda, O. Kitao, H. Nakai, T. Vreven, J.A. Montgomery Jr., J.E. Peralta, F. Ogliaro, M. Bearpark, J.J. Heyd, E. Brothers, K.N. Kudin, V.N. Staroverov, R. Kobayashi, J.
Normand, K. Raghavachari, A. Rendell, J.C. Burant, S.S. Iyengar, J. Tomasi, M. Cossi, N. Rega, J.M. Millam, M. Klene, J.E. Knox, J.B. Cross, V. Bakken, C. Adamo, J. Jaramillo, R. Gomperts, R.E. Stratmann, O. Yazyev, A.J. Austin, R. Cammi, C. Pomelli, J.W. Ochterski, R.L. Martin, K. Morokuma, V.G. Zakrzewski, G.A. Voth,

P. Salvador, J.J. Dannenberg, S. Dapprich, A.D. Daniels, O. Farkas, J.B. Foresman,

J.V. Ortiz, J. Cioslowski, D.J. Fox, Gaussian 09, Revision A.02, Gaussian Inc. Wallingford, CT, 2009.

24] N.L. Ma, Chem. Phys. Lett. 297 (1998) 230-238.

[25] R.F.W. Bader, Atoms in Molecules: A Quantum Theory, Oxford University Press, Oxford, 1990.

[26] AIMAll (Version 12.06.03), Todd A. Keith, TK Gristmill Software, Overland Park KS, USA, 2012 (aim.tkgristmill.com).

[27] R.F.W. Bader, C.F. Matta, F. Cortés-Guzmán, Organometallics 23 (2004) 6253 6263.

[28] M. Namazian, C.T. Lin, M.L. Coote, J. Chem. Theory Comput. 6 (2010) 2721 2725.

[29] A. Fojtik, A. Henglein, E. Janata, J. Phys. Chem. 96 (1992) 8203-8206; S. Remita, P. Archirel, M. Mostafavi, J. Chem. Phys. 1 (1995) 13198-13202. 